\title{
Shear behavior of crushed mudstone and claystone under macrostructural and microstructural approaches
}

\begin{abstract}
This article discussed the shear behavior of crushed mudstone and claystone in Malaysia when subjected to short- and long-term immersion while staged compression-immersiondirect shear tests were performed. The crushed mudrocks were subjected to 5 stages of loading (50 kPa, $100 \mathrm{kPa}, 150 \mathrm{kPa}, 300 \mathrm{kPa}$, and $600 \mathrm{kPa}$ ) with and without immersion, whereby immersions were done at $100 \mathrm{kPa}$ and $600 \mathrm{kPa}$ vertical loads were referred to as long- and short-term immersion tests, respectively. A variable pressure scanning electron microscope (VPSEM) and X-ray diffraction (XRD) were employed for microstructural investigation so as to give a microstructural description of crushed mudrock failure upon shearing. It is found that short-term immersion had caused the crushed mudrocks to be less brittle while long-term immersion resulted in fully plastic straining behavior for both crushed mudrocks. XRD results revealed that claystone contained higher swelling minerals compared to mudstone, which explains the clod-form of claystone seen in VPSEM images. Based on both macrostructural and microstructural investigation, it is found that the crushed mudrocks are more susceptible to failure under short-term immersion, while long-term immersion caused the crushed mudrocks to achieve a stable state and be less sensitive to further moisture changes.
\end{abstract}

